\title{
Cardiac arrest in the operating room requiring prolonged resuscitation
}

\section{Arrêt cardiaque en salle d'opération nécessitant une réanimation prolongée}

\author{
Ilia Charapov, MD $\cdot$ Naveen Eipe, MD
}

Received: 14 September 2011/ Accepted: 14 March 2012/Published online: 31 March 2012

(C) Canadian Anesthesiologists' Society 2012

\begin{abstract}
Purpose Prolonged cardiopulmonary resuscitation $(C P R)$ is often associated with limited success and poor long-term outcomes. The purpose of this report is to present the case of a patient who suffered an unanticipated cardiac arrest in the operating room and survived following a prolonged period of CPR.

Clinical features A previously healthy 53-yr-old male with inflammatory bowel disease was diagnosed with a perforated bowel and underwent emergency exploratory laparotomy under general anesthesia. Approximately two hours after induction of anesthesia, the patient experienced cardiac arrest, and for $55 \mathrm{~min}$, he underwent CPR and defibrillation according to the Advanced Cardiac Life Support (ACLS) protocols. As the decision to terminate CPR was being considered, a return of spontaneous circulation was detected 56 min after the onset of cardiac arrest. The patient survived with no major organ failure or adverse neurological outcome. No definitive cause of
\end{abstract}

Author contributions Ilia Charapov cared for the patient, obtained consent, carried out the case follow-up, and wrote and revised the manuscript. Ilia Charapov and Naveen Eipe prepared the case report and reviewed the literature. Naveen Eipe revised and submitted the final version of the manuscript.

This article is accompanied by an editorial. Please see Can J Anesth 2012; 59(6).

Electronic supplementary material The online version of this article (doi:10.1007/s12630-012-9698-4) contains supplementary material, which is available to authorized users.

I. Charapov, MD · N. Eipe, MD $(\bowtie)$

Department of Anesthesiology, The Ottawa Hospital (TOH),

University of Ottawa, Carling Ave. Suite B310, Ottawa,

ON K1Y 4E9, Canada

e-mail: neipe@toh.on.ca cardiac arrest was diagnosed in the postoperative period. At the follow-up 14 months after the event, the patient had returned to the pre-arrest level of functioning. The results of our literature search showed that no upper limit for the duration of CPR has been defined. Good outcomes after prolonged CPR depend on the patient's pre-arrest condition and the etiology of the cardiac arrest.

Conclusion Perioperative cardiac arrests are rare events, and there is little evidence to suggest an upper limit for the duration of resuscitation. Unknown etiologies and the presence of good patient predictors may support the continuation of prolonged CPR with good outcomes.

\section{Résumé}

Objectif Une réanimation cardiorespiratoire (RCR) prolongée est souvent associée à un succès limité et à un mauvais pronostic à long terme. L'objectif de ce rapport est de présenter le cas d'un patient ayant fait un arrêt cardiaque non anticipé en salle d'opération et ayant survécu après une RCR prolongée.

Caractéristiques cliniques Un homme âgé de 53 ans, jusque-là en bonne santé à l'exception d'une maladie inflammatoire intestinale, a présenté une perforation intestinale et a dî subir une laparotomie exploratoire d'urgence sous anesthésie générale. Approximativement deux heures après l'induction de l'anesthésie, le patient a fait un arrêt cardiaque et il a reçu une RCR pendant 55 minutes avec défibrillation conformément aux protocoles de réanimation cardiorespiratoire avancée (ACLS). Alors que la décision de mettre un terme à la RCR était envisagée, un retour à une circulation spontanée a été détecte 56 minutes après la survenue de l'arrêt cardiaque. Le patient a survécu sans défaillance d'un organe essentiel ni évolution neurologique préjudiciable. Aucune cause certaine de l'arrêt cardiaque n'a pu être diagnostiquée au 
cours de la période postopératoire. Lors du suivi, 14 mois après l'événement, le patient avait retrouvé le niveau d'activité qui était le sien avant l'arrêt cardiaque. Nos recherches dans la littérature ont montré qu'aucune limite supérieure de durée de la RCR n'a été définie. Un bon pronostic après $R C R$ prolongée dépend de l'état clinique $d u$ patient avant l'arrêt cardiaque et de l'étiologie de ce dernier.

Conclusion Les arrêts cardiaques périopératoires sont des événements rares et il y a peu de données probantes pour proposer une limite supérieure à la durée de la réanimation. Les étiologies inconnues et l'existence de facteurs prédictifs favorables liés au patient peuvent être en faveur de la poursuite d'une RCR prolongée avec de bons résultats.

While considered rare, intraoperative cardiac arrests in the operating room under general anesthesia are potentially catastrophic events. ${ }^{1}$ Intraoperative cardiac arrests may be anticipated in certain surgical procedures, for example when associated with blood loss, anaphylaxis, or other complications. ${ }^{2}$ However, unexpected cardiac arrests with poorly defined etiology present a challenge, especially with regard to the duration of cardiopulmonary resuscitation (CPR). ${ }^{3}$ We present a case of intraoperative cardiac arrest which was treated with prolonged CPR.

The patient has provided written consent for the reporting and publication of this case.

\section{Case report}

A 53-yr-old male (American Society of Anesthesiologists physical status IIIE, weight $64 \mathrm{~kg}$, height $166 \mathrm{~cm}$ ) presented with a suspected perforated colon secondary to inflammatory bowel disease (IBD) and was scheduled to undergo an emergency exploratory laparotomy. The patient was well until two months before surgery when he presented with abdominal pain and bleeding per rectum and was diagnosed with IBD. He had no known allergies, no known cardiorespiratory disorders, and excellent exercise tolerance. Five days before surgery, he was admitted to hospital for treatment with intravenous fluids, antibiotics, and steroids, and he was given a transfusion of two units of packed red blood cells. A radiological examination on the day of surgery revealed free air under the diaphragm suggestive of bowel perforation.

At the preanesthetic examination, the patient was febrile, diaphoretic, and appeared unwell. Standard monitors were applied, including a five-lead electrocardiogram
(ECG), a noninvasive blood pressure (BP) device, pulse oximetry, temperature, end-tidal $\mathrm{CO}_{2}$, oxygen and anesthetic agent analysis, and ventilatory pressure and volumes, and anesthesia was induced intravenously with fentanyl $200 \mu \mathrm{g}$, propofol $100 \mathrm{mg}$, and rocuronium $50 \mathrm{mg}$ (Figure, available as electronic supplementary material [ESM]). After tracheal intubation, anesthesia was maintained with desflurane in an air-oxygen mixture with controlled ventilation. Approximately $15 \mathrm{~min}$ after induction, the patient's BP decreased to $80 / 52 \mathrm{mmHg}$, and his heart rate (HR) increased to 127 beats. $\mathrm{min}^{-1}$ with associated ST changes on the ECG; a 2-mm ST elevation was seen in lead II, and a 1.3-mm depression was seen in V5. Phenylephrine $40 \mu \mathrm{g}$ and metoprolol $2 \mathrm{mg}$ were given intravenously with prompt resolution of the ECG abnormalities. Two units of packed red blood cells were rapidly transfused because the hemoglobin $(\mathrm{Hb})$ was $71 \mathrm{~g} \cdot \mathrm{L}^{-1}$. The ECG abnormalities normalized, and the BP and HR returned to the preanesthetic baseline and remained stable.

Eighty minutes after induction, the patient was given hydromorphone $1 \mathrm{mg} i v$ and ketamine $20 \mathrm{mg} i v$ as a bolus, followed by an infusion of $0.1 \mathrm{mg} \cdot \mathrm{kg}^{-1} \cdot \mathrm{hr}^{-1}$. At $100 \mathrm{~min}$, another dose of hydromorphone $1 \mathrm{mg} i v$ was administered, and a lidocaine infusion $2 \mathrm{mg} \cdot \mathrm{kg}^{-1} i v$, to be given over 12 min, was started. Six minutes later, ECG changes (ST elevation in II and ST depression in V5) were seen again, and the patient's BP had decreased to $85 / 50 \mathrm{mmHg}$ with a $\mathrm{HR}$ at 80 beats. $\min ^{-1}$. The lidocaine was stopped after $60 \mathrm{mg}$ had been administered. Phenylephrine $80 \mu \mathrm{g}$ was given intravenously, restoring the patient's BP to $96 / 72 \mathrm{mmHg}$ and HR to 77 beats. $\mathrm{min}^{-1}$. However, ST segments continued to deteriorate. As a nitroglycerine infusion was prepared but not infused, the patient's sinus rhythm changed to pulseless ventricular fibrillation (VF) six minutes after the onset of ST changes (112 min after induction). Up to this point, surgery had proceeded uneventfully with the surgeon about to excise the mobilized colon. A "resuscitation code" was called and another staff anesthesiologist was called to the operating room to assist. The surgery was halted and the surgeons started chest compressions without delay. One of the anesthesiologists checked the patient's carotid pulse every minute throughout resuscitation.

Biphasic defibrillation was initiated (150 J followed by $200 \mathrm{~J}$ ) and continued every three minutes. As VF continued, Advanced Cardiac Life Support (ACLS) guidelines for resuscitation were followed with the patient receiving epinephrine (total dose $9 \mathrm{mg}$ ), insulin (20 $\mathrm{U} i \mathrm{v}$ ), calcium chloride $(2 \mathrm{~g}), 50 \%$ dextrose $(50 \mathrm{~mL})$, sodium bicarbonate $(150 \mathrm{mEq})$, magnesium sulphate $(7 \mathrm{~g})$, and lidocaine (200 mg). Amiodarone $300 \mathrm{mg} i v$ was given at approximately $30 \mathrm{~min}$ after the arrest and then again at $40 \mathrm{~min}$ after the arrest (Figure, available as ESM). The quality of 
the chest compressions was continuously assessed by palpation of the carotid pulse and was described at all times as "brisk upstroke with chest compressions". Throughout CPR, the surgeon observed that bowel mucosa continued to be pink and well perfused. Given the nature of ST segment changes before the arrest, an urgent cardiology consultation was requested to consider coronary angiography and intervention while resuscitative efforts continued. The cardiologist recommended no change in management. At $41 \mathrm{~min}$ from the onset of the arrest, the patient continued to be in treatment-resistant VF. Biphasic defibrillation was repeated every four to five minutes and chest compressions were continued. At $43 \mathrm{~min}$ from the arrest, sinus rhythm changed to slow pulseless electrical activity (PEA). Atropine $3 \mathrm{mg} i v$ was administered and the ACLS guidelines for slow PEA were followed for another ten minutes.

At 53 min after cardiac arrest, the decision to terminate resuscitation was being discussed; however, at 56 min after the arrest, while slow PEA persisted, a weak carotid pulse was felt for the first time. Sinus bradycardia improved with atropine to a normal sinus rhythm, and circulation returned 56 min after the onset of cardiac arrest. A review of the patient's electronic anesthesia record after the event revealed that the recorded range (minimum-maximum) of end-tidal $\mathrm{CO}_{2}\left(\mathrm{EtCO}_{2}\right)$ doubled from 6-17 $\mathrm{mmHg}$ during the first $45 \mathrm{~min}$ of resuscitation to a consistent $21-30 \mathrm{mmHg}$ during the last $11 \mathrm{~min}$ of CPR. The patient's hemodynamic variables stabilized (BP 158/99 mmHg, HR 76 beats. min $^{-1}$, oxygen saturation $\left.\left(\mathrm{SpO}_{2}\right) 93 \%, \mathrm{EtCO}_{2} 35 \mathrm{mmHg}\right)$ with an infusion of norepinephrine. A cannula was inserted in the radial artery, and a central venous catheter was placed in the right internal jugular vein. A pulmonary artery catheter was floated within ten minutes of return of spontaneous return of circulation; first pulmonary arterial pressure (PAP) was 25/10 $\mathrm{mmHg}$. Arterial blood gas analysis $35 \mathrm{~min}$ post-arrest revealed $\mathrm{pH} 7.0, \mathrm{PaCO}_{2} 48 \mathrm{mmHg}, \mathrm{PaO}_{2} 150 \mathrm{mmHg}$, base excess $16 \mathrm{mmol} \cdot \mathrm{L}^{-1}, \mathrm{HCO}_{3} 14.3 \mathrm{mmol} \cdot \mathrm{L}^{-1}$, oxygen saturation $98 \%, \mathrm{~K} 3.4 \mathrm{mmol} \cdot \mathrm{L}^{-1}$, Na $134 \mathrm{mmol} \cdot \mathrm{L}^{-1}, \mathrm{Hb}$ $99 \mathrm{~g} \cdot \mathrm{L}^{-1}$, international normalized ratio (INR) 3 , and glucose $22.2 \mathrm{mmol} \cdot \mathrm{L}^{-1}$.

The patient remained stable and ST segments normalized to baseline over ten minutes. There were no changes on the 12-lead ECG which would have warranted a cardiology intervention. The surgeons proceeded expeditiously to excise the already mobilized segment of perforated bowel and create a colostomy. The patient was then transferred to the intensive care unit (ICU) with an intubated trachea and ventilated lungs, and he remained stable (BP 115/60 $\mathrm{mmHg}$ and HR 80 beats $\cdot \mathrm{min}^{-1}$ ) on an intravenous infusion of norepinephrine. The ICU team decided not to initiate cooling protocol for this patient.

In the ICU, bedside transthoracic echocardiography showed global hypokinesia. On postoperative day 1 , the patient was weaned from inotropic support. A coronary angiography showed diffuse and mild coronary disease with no treatable lesions. A computed tomography scan revealed a small subsegmental pulmonary embolism. Three days after his initial surgery, the patient returned to the operating room to close the abdominal incision, and he was weaned from the ventilator uneventfully. He was formally evaluated by the ICU team and found to have a normal neurological examination. The patient was interviewed by the anesthesiologist prior to discharge and was found to have no recall of events and no apparent neurological deficits. He was discharged to the ward and then to home and normal level of activity with a well functioning colostomy. Fourteen months after his cardiac arrest, the patient underwent surgery for reversal of his colostomy. The patient has since returned to work and a normal level of activity. A neurologist did not perform a formal neurological assessment and no objective cognitive function testing was carried out in this patient.

\section{Discussion}

We have reported a case of unexpected intraoperative cardiac arrest in a patient with IBD undergoing emergency colon resection for a perforated bowel. The etiology of this cardiac arrest is unclear. The presence of anemia and ECG changes immediately after induction of anesthesia along with a reappearance of ECG abnormalities just prior to cardiac arrest makes reversible coronary vasospasm a possible primary mechanism of cardiac arrest. This opinion is supported by the postoperative coronary angiography. In our view, sepsis-induced cardiomyopathy was also a possibility considering the patient's long septic illness preoperatively and the timing of his cardiac arrest at the end of a long surgical dissection of necrotic bowel tissue. ${ }^{4}$ A pharmacologically mediated sympathectomy by the combination of opioids, a beta-blocker, ketamine, a volatile agent, and lidocaine may have also contributed to the mechanism. With regard to management of cardiac arrest, the patient received immediate uninterrupted resuscitation guided by ACLS protocol. In retrospect, the first dose of amiodarone could have been given sooner than at the 30-min time point. An important sign was the upward capnography trend toward the end of the pulseless period-unrecognized at the time of CPR-possibly heralding return of spontaneous circulation. In our opinion, trends towards improvement of pulmonary blood flow suggested by capnography should encourage continued resuscitatory efforts.

We undertook a literature review with regard to the duration and outcomes of CPR. Databases (OVID, Medline, and Embase) were searched for the period 1990 to 2010 with the keywords: CPR and duration or 


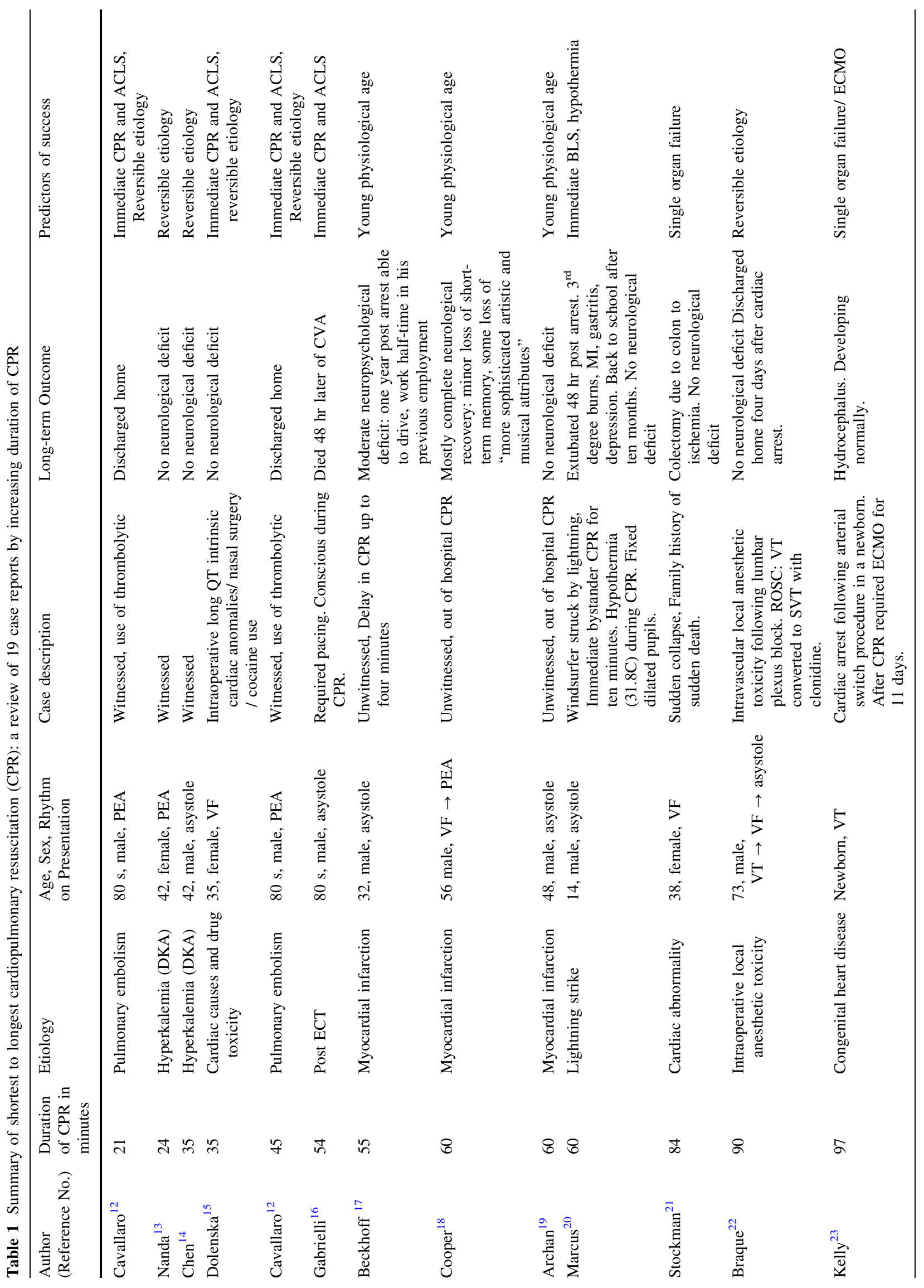




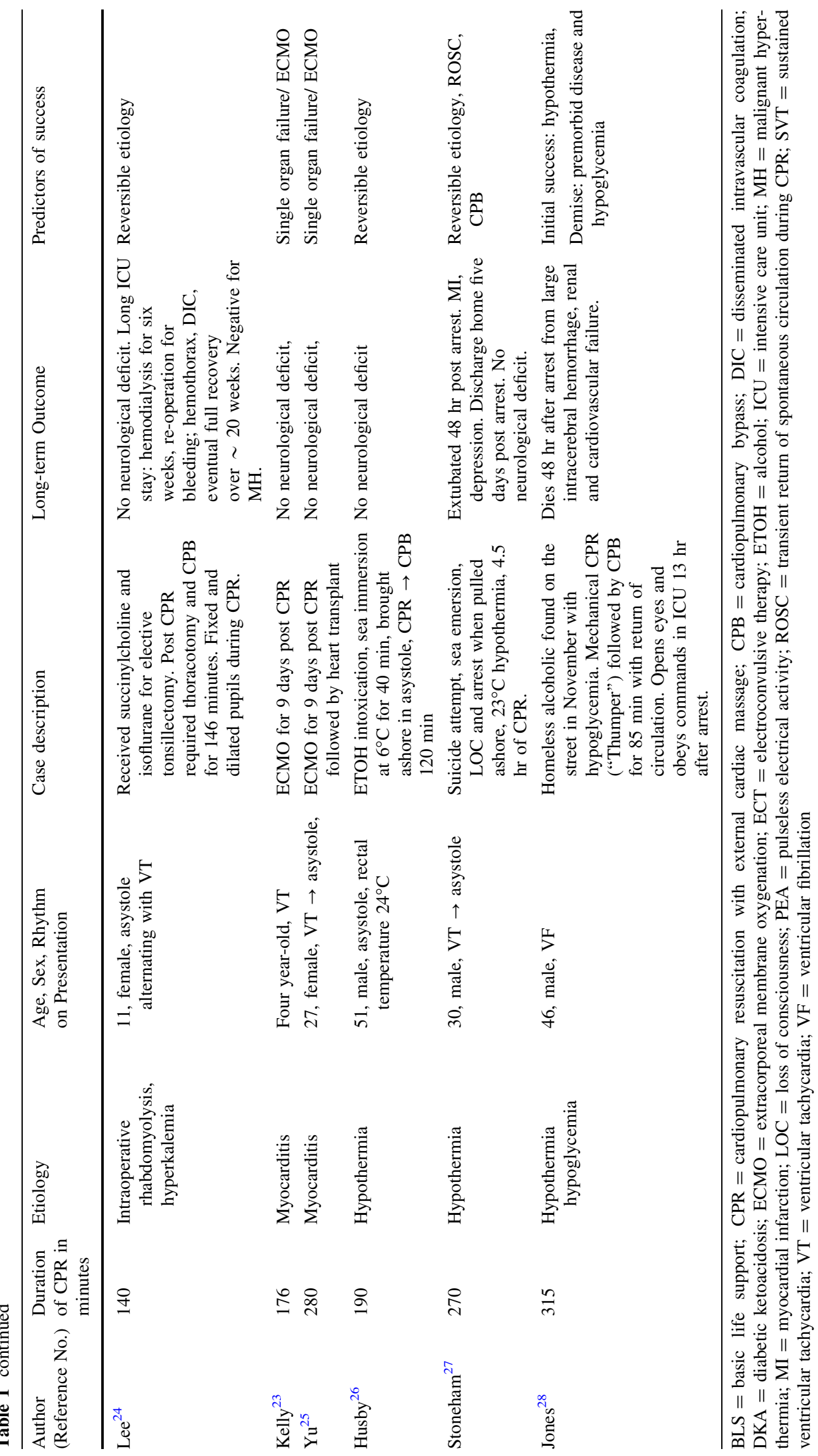


cardiopulmonary resuscitation and duration or prolonged and CPR or prolonged and resuscitation. The results were limited to English language citations. The case reports were organized according to duration of resuscitation (Table 1), and they were summarized according to factors predicting outcomes of these efforts (Table 2) and criteria for continuing resuscitation (Table 3 ).

The literature search revealed case reports of resuscitation after cardiac arrest which varied from 21 to $315 \mathrm{~min}$ (Table 1). The results of this search suggest that certain patient factors present before CPR is started may predict a positive outcome. The factors are summarized for CPR after all-cause cardiac arrest (Table 2). While presence of these factors may support prolonged resuscitation, the duration of such prolonged CPR seems to be poorly defined. It is important to emphasize that case reports of successful and unusually long resuscitations are biased because cases of prolonged resuscitation with poor outcomes may remain unreported or even undetected by our English language literature search. Nevertheless, the successful case reports do provide valuable information to help identify common features of successful resuscitations which could support prolonged resuscitatory efforts.

There are published guidelines which may be useful to guide resuscitation of in-hospital cardiac arrest in general. However, these recommendations may not be applicable to the perioperative setting. Perioperative cardiac arrests occur infrequently (estimated to be 0.69 per 10,000 anesthetics). While it is estimated that only one-third of these patients survive CPR, only $70 \%$ of these survivors are discharged home without major organ dysfunction. ${ }^{5}$ The duration of CPR also influences survival and outcomes. ${ }^{6}$ A review of all in-hospital cardiac arrests suggests that just under one-half of all cardiac arrests were immediately resuscitated successfully by $28 \mathrm{~min}$ of $\mathrm{CPR}$; the survival rate decreases considerably beyond 28 min of CPR. ${ }^{6}$ The prognosis for long-term survival is also related to the duration of CPR; in the same series, no patients requiring CPR for longer than 15 min survived for more than six weeks. Another review of 14,720 all-cause cardiac arrests revealed that the probability of survival decreases rapidly if CPR lasts longer than ten minutes. ${ }^{7}$ It is important to accentuate that cases of perioperative cardiac arrest are underrepresented in this series. For CPR in critical care units, a more recent study reports a $26.7 \%$ survival to discharge, with mortality increasing with duration of CPR and only one-third of patients surviving CPR which lasted more than 45 min. $^{8}$

Neither ACLS nor European Resuscitation Council (ERC) guidelines commit to a maximum duration of CPR before considering continued resuscitation futile, and both seem to conclude that rules for clinical decision-making cannot be recommended due to lack of prospective validation. ${ }^{9,10}$ Other guidelines suggest that patient context, setting of cardiac arrest, and promptness and quality of resuscitation are the most important factors to consider. ${ }^{11}$ After reviewing the literature, we are of the opinion that an appropriate duration of CPR is difficult to define, and the definition depends entirely on the context of patient presentation.

Table 2 Summary of outcome predictors for resuscitation from all-cause cardiac arrest

Predictors of successful outcome at the start of CPR: (success and good neurologic outcome)

- Witnessed arrest and VF/VT presentation: $60-88 \%$ survival

- Witnessed arrest and asystole / PEA presentation: $33 \%$ survival $^{6}$

- In-hospital arrest in actively monitored area, e.g., OR, $\mathrm{PACU}^{7}$

- Arrest during daytime ${ }^{29}$

- Immediate start of BLS by bystander (within four minutes or less) ${ }^{29}$

- Early ACLS / a short ambulance response time: less than ten minutes ${ }^{29}$

- Immediate defibrillation if shockable rhythm (within three minutes) ${ }^{7,29}$

- Reversible cause, e.g., hypothermia, metabolic / electrolytes abnormalities, toxins / drug overdose

- Transient ROSC at any point of $\mathrm{CPR}^{9,10}$

Predictors of poor outcome at the start of CPR: (failure and/or major organ failure or death)

- Unwitnessed arrest and VF/VT presentation: $17 \%$ survival $^{6,29}$

- Unwitnessed arrest and asystole / PEA presentation: 2-13\% survival ${ }^{6,29}$

- Out of hospital arrest / location in hospital without active monitoring ${ }^{6,29}$

- Night time ${ }^{6}$

- Associated illness or nursing home residency with dependent status: DM, end stage organ failure, advanced cancer ${ }^{6}$

- Absent pupillary responses during resuscitation ${ }^{6,20}$

- Absent or low end-tidal $\mathrm{CO}_{2}{ }^{6}$

$\mathrm{BLS}=$ basic life support; $\mathrm{CPR}=$ cardiopulmonary resuscitation with external cardiac massage; DM = diabetes mellitus; $\mathrm{OR}=$ operating room; $\mathrm{PACU}=$ postanesthesia care unit; $\mathrm{PEA}=$ pulseless electrical activity; $\mathrm{ROSC}=$ transient return of spontaneous circulation during $\mathrm{CPR} ; \mathrm{VT}=$ ventricular tachycardia; $\mathrm{VF}=$ ventricular fibrillation 
Table 3 Summary of factors that support extending or limiting the duration of CPR

\section{What would support extending CPR?}

- Etiology of arrest: reversible cause, e.g., hypothermia, metabolic or electrolyte abnormality, toxins or medication overdose, uncertain etiology of arrest: time needed to make definitive diagnosis ${ }^{30}$

- $\mathrm{CPR}$ to bridge to extracorporeal circulation ${ }^{29}$

- Persistent $\mathrm{VF}^{10}$

- Temporary ROSC during CPR ${ }^{11}$

- Young physiological age: discrepancy between chronological and physiological age (controversial) ${ }^{7,10}$

- Good quality CPR (evidence of organ perfusion) ${ }^{11}$

What would support limiting duration of CPR?

- Absence of good predictors at the start of CPR or Presence of bad predictors at the start of CPR (see Table 2)

- Asystole for $>20 \mathrm{~min}^{10}$

- Irreversible cause $\mathrm{e}^{9,10}$

- Long time to $\mathrm{CPR}^{11}$

- Poor functional pre-arrest state ${ }^{29}$

$\mathrm{CPR}=$ cardiopulmonary resuscitation with external cardiac massage; $\mathrm{ROSC}=$ transient return of spontaneous circulation during $\mathrm{CPR}$; $\mathrm{VF}=$ ventricular fibrillation

While this case report may not necessarily reflect novelty or innovation in treatment, it may encourage others to persevere in the resuscitation of patients suffering a cardiac arrest of unknown etiology or patients with factors supporting prolonged resuscitation (summarized in Table 3 ).

In conclusion, this case presents prolonged resuscitation with survival, excellent neurological outcome, no major organ damage, and return to a normal level of functioning. Factors influencing such outcome were the patient's young age, excellent functional status, and ultimately reversible etiology of cardiac arrest treated with immediate and goodquality CPR. The context of each case of cardiac arrest should be carefully considered to avoid CPR which is unnecessarily long and futile. There is currently no available evidence with regard to establishing duration of resuscitation efforts, particularly in the perioperative setting. Expert opinion is required to define what would be considered as "futile" duration of CPR.

Acknowledgements We acknowledge Dr. David Ewing's assistance with the conduct of patient resuscitation in the operating room. We also acknowledge the assistance of Ms. Alexandra Davis, a medical librarian at The Ottawa Hospital, who helped us with the literature search.

Conflicts of interest and sources of support None declared.

\section{References}

1. An JX, Zhang LM, Sullivan EA, Guo QL, Williams JP. Intraoperative cardiac arrest during anesthesia: a retrospective study of 218,274 anesthetics undergoing non-cardiac surgery. Chin Med J (Engl) 2011; 124: 227-32.

2. Messahel FM, Al-Qahtani AS. Incidence of perioperative cardiac arrest: analysis of anesthetics over 18-year period. Middle East J Anesthesiol 2010; 20: 815-9.
3. Mhyre JM, Ramachandran SK, Kheterpal S, Morris M, American Heart Association National Registry for Cardiopulmonary Resuscitation Investigators. Delayed time to defibrillation after intraoperative and periprocedural cardiac arrest. Anesthesiology 2010; 113: 782-93.

4. Flynn A, Chokkalingam Mani B, Mather PJ. Sepsis-induced cardiomyopathy: a review of pathophysiologic mechanisms. Heart Fail Rev 2010; 15: 605-11.

5. Girardi LN, Barie PS. Improved survival after intraoperative cardiac arrest in noncardiac surgical patients. Arch Surg 1995; 130: $15-8$.

6. Saklayen $M$, Liss $H$, Markert $R$. In-hospital cardiopulmonary resuscitation. Survival in 1 hospital and literature review. Medicine (Baltimore) 1995; 74: 163-75.

7. Peberdy MA, Kaye W, Ornato JP, et al. Cardiopulmonary resuscitation of adults in the hospital: a report of 14720 cardiac arrests from the National Registry of Cardiopulmonary Resuscitation. Resuscitation 2003; 58: 297-308.

8. Kutsogiannis DJ, Bagshaw SM, Laing B, Brindley PG. Predictors of survival after cardiac or respiratory arrest in critical care units. CMAJ 2011; 183: 1589-95.

9. Morrison LJ, Kierzek G, Diekema DS, et al. Part 3: ethics: 2010 American Heart Association Guidelines for Cardiopulmonary Resuscitation and Emergency Cardiovascular Care. Circulation 2010; 122: S665-75.

10. Nolan JP, Soar J, Zideman DA, et al. European Resuscitation Council Guidelines for Resuscitation 2010 Section 1. Executive summary. Resuscitation 2010; 81: 1219-76.

11. van Walraven C, Forster AJ, Parish DC, et al. Validation of a clinical decision aid to discontinue in-hospital cardiac arrest resuscitations. JAMA 2001; 285: 1602-6.

12. Cavallaro F, Sandroni C, Bocci MG, Marano C. Good neurological recovery after cardiopulmonary resuscitation and thrombolysis in two old patients with pulmonary embolism. Acta Anaesthesiol Scand 2009; 53: 400-2.

13. Nanda $U$, Willis A. A successful outcome of prolonged resuscitation of cardiac arrest with pulseless electrical activity (PEA) due to severe hyperkalaemia. N Z Med J 2009; 122: 3561.

14. Chen HT, Ong JR, Hung SW, Lin LW, Chong CF. Survival after prolonged resuscitation from cardiac arrest in a case of severe diabetic ketoacidosis. Am J Emerg Med 2006; 24: 633-4.

15. Dolenska $S$. Intraoperative cardiac arrest in acquired long QT syndrome. Br J Anaesth 2009; 102: 503-5. 
16. Gabrielli A, Layon AJ, Cole P, Holbert R, Modell JH. Prolonged cardiopulmonary resuscitation with preservation of cerebral function in an elderly patient with asystole after electroconvulsive therapy. J Clin Anesth 2002; 14: 234-40.

17. Beckhoff A, Burgi A, Ummenhofer $W$. Good reasons for prolonged resuscitation. Resuscitation 2005; 66: 395-6.

18. Cooper S, Macnaughton P. Prolonged resuscitation: a case report. Resuscitation 2001; 50: 349-51.

19. Archan S, Prause G, Kugler B, Gumpert R, Giacomini G. Successful prolonged resuscitation involving the use of tenecteplase without neurological sequelae. Am J Emerg Med 2008; 26: 1068.e5-7.

20. Marcus MA, Thijs N, Meulemans AI. A prolonged but successful resuscitation of a patient struck by lightning. Eur J Emerg Med 1994; 1: 199-202.

21. Stockman W, De Keyser J, Brabant $S$, et al. Colon ischaemia and necrosis as a complication of prolonged but successful CPR. Resuscitation 2006; 71: 260-2.

22. Braque S, Bernard-Bertrand $F$, Guillou $N$, Guezennec D, Canciani JP, Gentili ME. Successful but prolonged resuscitation after local anesthetic-induced cardiac arrest: is clonidine effective? Acta Anaesthesiol Belg 2008; 59: 91-4.

23. Kelly RB, Porter PA, Meier AH, Myers JL, Thomas NJ. Duration of cardiopulmonary resuscitation before extracorporeal rescue: how long is not long enough? ASAIO J 2005; 51: 665-7.
24. Lee G, Antognini JF, Gronert GA. Complete recovery after prolonged resuscitation and CPB for hyperkalemic cardiac arrest. Anesth Analg 1994; 79: 172-4.

25. Yи HY, Yeh HL, Wang SS, et al. Ultra long cardiopulmonary resuscitation with intact cerebral performance for an asystolic patient with acute myocarditis. Resuscitation 2007; 73: 307-8.

26. Husby P, Andersen KS, Owen-Falkenberg A, Steien E, Solheim J. Accidental hypothermia with cardiac arrest: complete recovery after prolonged resuscitation and rewarming by extracorporeal circulation. Intensive Care Med 1990; 16: 69-72.

27. Stoneham MD, Squires SJ. Prolonged resuscitation in acute deep hypothermia. Anaesthesia 1992; 47: 784-8.

28. Jones AI, Swann IJ. Prolonged resuscitation in accidental hypothermia: use of mechanical cardio-pulmonary resuscitation and partial cardio-pulmonary bypass. Eur J Emerg Med 1994; 1: 34-6.

29. So HY, Buckley TA, Oh TE. Factors affecting outcome following cardiopulmonary resuscitation. Anaesth Intensive Care 1994; 22: 647-58.

30. Lechleitner P, Schinnerl A, Luef G, Baubin M, Dienstl A, Kroesen $G$. Prolonged resuscitation efforts. Lancet 1992; 339: 683-4. 